\title{
Effect of Gap Light Factors on Understory Plants Species Distribution in
}

\section{Different Forest Types}

\author{
Yu-Dan Sun ${ }^{+}$, Jin-Xiang Liu ${ }^{+}$, Huo-Bin Xiong,Yan-hua Feng and Li tong
}

Life Science and Technology School, Lingnan Normal University, Zhanjiang, 524048, China

Burningice80@163.com, lightlong@163.com, 1831208028@qq.com,348492967@qq.com,2512309094@qq.com

+The author contributed equally to this work

*For correspondence: Burningice80@163.com

Keywords: Understory Plants; Gap Light Factors; Multi-Response Permutation Procedures; Indicator Species Analysis ;Canonical Correspondence Analysis

Abstract: This paper taking 4000 square meter sample survey data of different forest types in Zhanjiang as the research basis. Analyzed the structure and composition of understory plants by different gap light factor. Results showed that the impact of gap light on species distribution is significant. Indicator species of canopy openness is Eucalyptus exserta and Melia azedarach;the indicator species of understory diffuse radiation include Eucalyptus exserta, Melia azedarach, Acacia mangium, Alocasia macrorrhiza, Pteris semipinnata and Eupatorium odoratum; the indicator species of understory diffuse radiation include Eucalyptus exserta, Glycosmis pentaphylla, Sterculia lanceolata, Ficus hispida, Wedelia chinensis and Acacia mangium; the indicator species of understory total radiation include Eucalyptus exserta, Melia azedarach, Acacia mangium, Alocasia macrorrhiza and Pteris semipinnata.

\section{Introduction}

Understory plants has a very important contribution to the ecosystem. It could protected the biodiversity, ensure the productivity of the ecosystem, keep the soil and water conservation, promoting nutrient cycle, restore vegetation and provide habitat for wildlife, etc. $[1,2,3]$. The distribution of understory plants and canopy structure, light conditions, soil and other environmental factors are closely related in forest ecosystems, Either factor change can cause understory plants on the environment and the change of the effective utilization of resources, thus affect the composition and distribution of understory plants [4]. The amount and type of understory plants will change along with the dynamic of forest canopy structure [5]. The canopy openness has a great influence on the distribution of the understory plants [6]. Because the light is one of the main factors of plants on live and grow, the canopy openness of the forest will cause different forests light intensity, temperature and moisture conditions which affect the forest $[7,8]$, Which is also the important factors that affects the composition and diversity of understory plants. Canopy structure's influence on the distribution patterns of understory plants mainly in the canopy structure factor of light control, understory light environment is a very important factor on the growth process, succession and a series of ecology of understory plants[9]. A large number of research results show that canopy openness degree directly affect the forest understory light resource distribution[10-13], and the availability of the optical resources directly affects the growth of the plant photosynthesis, so to determine the distribution of species in the forests [14-16].

This paper taking 4000 square meter sample survey data of different forest types in Zhanjiang as the research basis. Analyzed the structure and composition of understory plants by different gap 
light factor. Aimed to explore understory plants with different illumination of the response and reveal different illumination and understory plants distribution of the relationship. Analyses the indicator of the understory plants and gap light factors, has been clear about the light of the different indicator species, has important theoretical significance for the research of forest understory plants restoration .

\section{Methods}

\section{Sample design and investigation}

Selected 4000 square meter sample area was divided into 40 samples of $10 * 10$ in main park for example Sanlingsan forest park, Cunjinqiao park, Lake rock scenic spot in Zhanjiang. In the middle of each quadrat and corners were selected $2 * 2$ small kind party total of five, detailed records within the small kind side herbal shrub tree saplings $(\mathrm{DBH}<3 \mathrm{~cm})$ on the number of species coverage on average height, etc.

Choose the digital camera (model Nikon4500) as an external fisheye lens in the center of each $10 * 10$ samples get a canopy image, When shooting using the camera tripod support in from the ground 1.3-1.6 meters and placed in a horizontal position.

\section{Data statistics and analysis}

Each of the samples taken canopy image is analyzed using GLA (gap light analyer) software and a series of canopy structure and understory light parameters are obtained. The parameters of canopy structure include CO(Canopy Openness) and LAI(Leaf Area Index). The parameters of understory light contain Trans Dir(Transmitted Direct Solar Radiation), Trans Dif(Transmitted Diffuse Solar Radiation) and Trans Tot(Transmitted Total Solar Radiation).

The differences between vegetation species composition and gap light factors is analyzed by MRPP (Multi - Response Permutation Procedures). No multiple differences between inspection group tested using ISA(Indicator species analysis), describe each species group of the separation between the situation. Sort the relationship between species and environmental factors by CCA(Canonical Correspondence Analysis). The significant between each environment variable measurement and species is tested by Monte Carlo. The index analysis of MRPP and ISA using the software PC - ORD5.0.The analysis of CCA using the software Canoco for windows 4.5.

\section{Result and analysis}

\section{Gap light factors to different groups of the species composition of differences}

Analysis results of MRPP (table 1)show that the P values of four forests in the light factor were less than 0.05, explained that the grouping of gap light factors in the influence of the distribution of understory plants has significant difference. The grouping boundaries between CO and Trans Dif which have biggish $\mathrm{T}$ is not obvious $(\mathrm{P}<0.05)$, but the grouping boundaries between Trans Dir and Trans Tot has visible difference $(\mathrm{P}>0.05)$. A value is indicate high consistency within the group. See from the data, the group of Trans Dir and Trans Tot has high consistency, Trans Dif followed, CO is the consistency of the worst in the group.

Table.1 Multi-response permutation procedures of understory plant species and gap light factors

\begin{tabular}{cccc}
\hline Gap Light Factors & $T$ & $A$ & $P$ \\
Canopy Openness & -2.4402062 & 0.03964444 & 0.02261499 \\
Transmitted Direct Solar Radiation & -5.0686031 & 0.08303079 & 0.00040619 \\
Transmitted Diffuse Solar Radiation & -2.6459667 & 0.04359737 & 0.01730329 \\
Transmitted Total Solar Radiation & -4.4767108 & 0.07247994 & 0.00098141 \\
\hline
\end{tabular}




\section{The indicator species analysis of gap light}

This paper act indicate value of $\geq 25$ and $\mathrm{P} \leq 0.05$ species as illumination factor of the indicator species(table2-table5). Results show that the indicator species of CO is Eucalyptus exserta and Melia azedarach;the indicator species of understory diffuse radiation include Eucalyptus exserta, Melia azedarach, Acacia mangium, Alocasia macrorrhiza, Pteris semipinnata and Eupatorium odoratum; the indicator species of understory diffuse radiation include Eucalyptus exserta, Glycosmis pentaphylla, Sterculia lanceolata, Ficus hispida, Wedelia chinensis and Acacia mangium; the indicator species of understory total radiation include Eucalyptus exserta, Melia azedarach, Acacia mangium, Alocasia macrorrhiza and Pteris semipinnata. Among them, Eucalyptus exserta and Acacia mangium are indicator species of four groups.

Table.2 Indicator species analysis ( ISA ) of canopy openness

\begin{tabular}{cccc}
\hline Species & Indicating value of the largest groups & IV (indicated value) & $P$ \\
Eucalyptus exserta & 4 & 50.5 & 0.0008 \\
Melia azedarach & 4 & 28.2 & 0.0088 \\
\hline
\end{tabular}

$P$ is taken from 4999 random inspection(Monte Carlo test)

Tab.3 Indicator species analysis ( ISA ) of understory direct radiation

\begin{tabular}{cccc}
\hline Species & Indicating value of the largest groups & IV (indicated value) & $P$ \\
Eucalyptus exserta & 4 & 66.7 & 0.0002 \\
Melia azedarach & 4 & 44.4 & 0.0012 \\
Acacia mangium & 4 & 46.1 & 0.0022 \\
Alocasia macrorrhiza & 3 & 45.2 & 0.0024 \\
Pteris semipinnata & 3 & 33 & 0.0128 \\
Eupatorium odoratum & 3 & 27.7 & 0.0424 \\
\hline
\end{tabular}

$P$ is taken from 4999 random inspection(Monte Carlo test)

Table.4 Indicator species analysis ( ISA) of understory diffuse radiation

\begin{tabular}{cccc}
\hline Species & Indicating value of the largest groups & IV (indicated value) & $P$ \\
Eucalyptus exserta & 4 & 35.3 & 0.0114 \\
Glycosmis pentaphylla & 1 & 32.3 & 0.013 \\
Sterculia lanceolata & 1 & 32.1 & 0.0176 \\
Wedelia chinensis & 3 & 25 & 0.0336 \\
Ficus hispida & 3 & 29 & 0.0386 \\
Acacia mangium & 4 & 29.5 & 0.045 \\
\hline \multicolumn{5}{c}{ Table.5 Indicator species analysis( ISA) of understory total radiation } \\
\hline \multicolumn{5}{c}{ Species } & Indicating value of the largest groups & \\
Eucalyptus exserta & 4 & 54.5 & $P$ \\
Melia azedarach & 4 & 36.4 & 0.0002 \\
Acacia mangium & 4 & 35.7 & 0.0012 \\
Pteris semipinnata & 3 & 27.5 & 0.0068 \\
Alocasia macrorrhiza & 3 & 27.8 & 0.0102 \\
\hline
\end{tabular}

$P$ is taken from 4999 random inspection(Monte Carlo test)

Table.6 Correletions of gap light factors with axis, eigenvalues and cumulative percentages of variance explained from CCA ordinations

\begin{tabular}{cccc}
\hline gap light & Axis 1 & Axis 2 & Axis 3 \\
co & -0.100 & -0.221 & 0.470 \\
Tr & -0.497 & 0.151 & 0.246 \\
Tf & -0.339 & -0.150 & 0.464 \\
Tt & -0.459 & 0.037 & 0.345
\end{tabular}




$\begin{array}{cccc}\text { LAI } & 0.122 & 0.055 & -0.451 \\ \text { Eigenvalues } & 0.566 & 0.256 & 0.144 \\ \text { Cumulative percentage \% } & 9.1 & 13.3 & 15.6\end{array}$

\section{The CCA of correlation between species distribution and gap light}

The analysis of MRPP and ISA show that the impact of gap light on species distribution is significant. So we could proceed CCA on the relationship between species distribution and gap light. To investigate the understory plant species composition and the environmental factor obtained form data matrix and use CCA get the CCA two-dimensional sequence diagram(figure1). Analysis of gap light factor and CCA sort the relationship between the axis can be seen that the eigenvalues on gap light of was 0.566, 0.266 and 0.144, cumulative percentage was 9.1,13.3 and 15.6. We also could conclude that the third order axial of environmental factors has the strongest influence on distribution of understory plants(table6). From the dependency we deduced the strongest influence on the distribution of understory plants is CO and Tf, second places is Tt, and the most weak is Tr. Also can be seen that the included angle between $\mathrm{CO}$ and the third order shaft is minimum. It explained that the abundance of understory plants is greater with greater $\mathrm{CO}$ (figure 1 ).

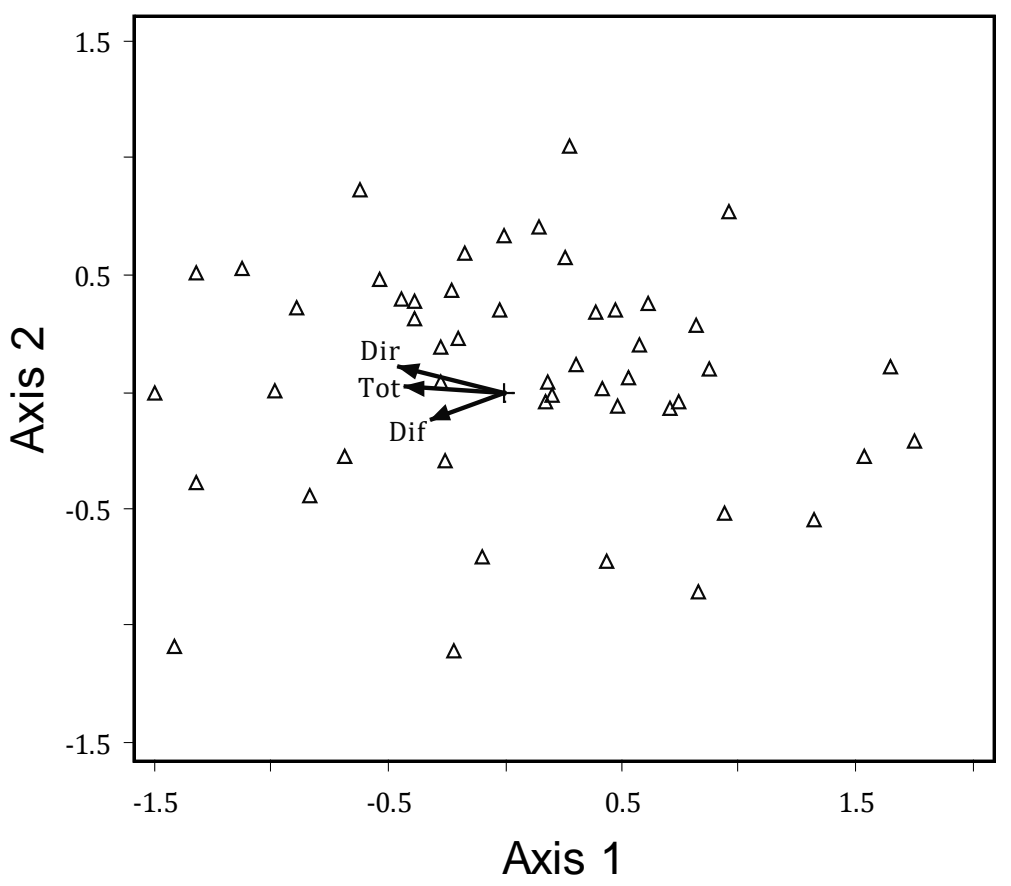




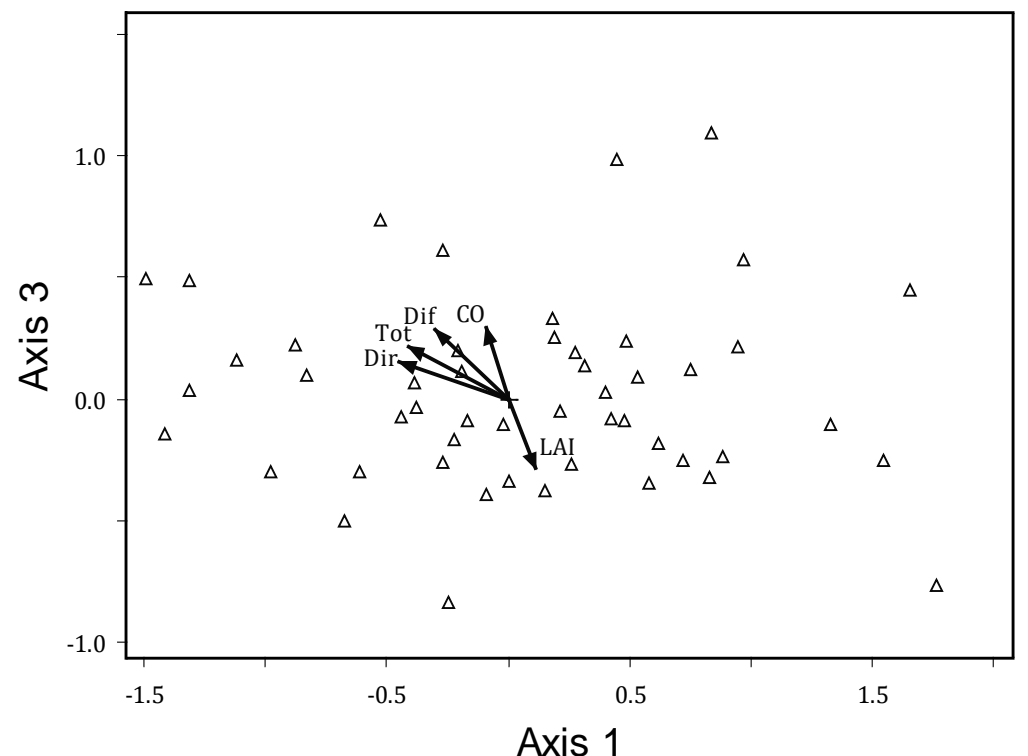

$\triangle$ : Understory plant species; Co ( Canopy Openness ); Tr ( Understory Direct Radiation ); Tf ( Understory Diffuse Radiation ); Tt ( Understory Total Radiation ); LAI ( Indicator Species Analysis )

Fig.1 CCA ordination for understory plant species and gap light factors

\section{Discussion}

Plant species composition formed the canopy, the change of the canopy influenced gap light, impact on understory plants thereby. So the relationship between the environment and plant is close and complex. the change of gap light could affected the decomposition and metabolism of organic material of the soil, , and the use of plants. The development, growth and distribution of vegetation, such as structure will produce certain effect. Related studies have shown that gap light affect plant growth, development and succession of one of the most important factor.

The gap light have significant effect on the distribution of the understory plants. As can be seen from the analysis result that $\mathrm{CO}$, $\mathrm{Tr}$, $\mathrm{Tf}$ and $\mathrm{Tt}$ distribution of understory plants has significant instruction function, and the plant community distribution and succession in the region play an important influence. All factors have common indicator species for Eucalyptus exserta and Acacia mangium, that means the two species have a sensitive reaction on gap light. Woody plants is mainly in indicator species, showed that gap light has guiding function in distribution of woody plants. Indicator species analysis and CCA can studied the characteristics of environmental factors on the understory plants distribution. Has an important theoretical significance on restoration and reconstruction of the understory plants, At the same time as the suitable planting tree species selection also has a certain guiding significance.

\section{Acknowledgements}

This research is supported by National Spark Program of China (Grants: 2013GA780075) and Zhanjiang key laboratory project of tropical plant resources and development (No. 2014A06008). 


\section{References}

[1] Kerns B K, Thies W G, Niwa C G. Season and severity of prescribed burn in ponderosa pine forests: implications for understory native and exotic plants. Ecoscience.2006 (13): 44-55

[2] Dodson E K, Peterson D W, Harrod R J. Understory vegetation response to thinning and burning restoration treatments in dry conifer forests of the eastern Cascades, USA. Forest Ecology and Management.2008 (255): 3130-3140

[3] Zenner E K, Berger A L. Influence of skidder traffic and canopy removal intensities on the ground flora in a clearcut-with-reserves northern hardwood stand in Minnesota, USA. Forest Ecology and Management.2008 (256): 1785-1794

[4] Small C J, McCarthy B C. Spatial and temporal variability of herbaceous vegetation in an eastern deciduous forest. Plant Ecology.2003(164): 37-48

[5] Beckage B, Clark J S, Clinton B D, et al. A long-term study of tree seedling recruitment in southern Appalachian forests: the effects of canopy gaps and shrub understories. Canadian Journal of Forest Research.2000(30): 1617-1631

[6] Kincaid J A, Parker A J. Structural characteristics and canopy dynamics of Tsuga Canadensis in forests of the southern Appalachian Mountains, USA. Plant Ecology.2008(199): 265-280

[7] De Kovel C G et al. Carbon and nitrogen in soil and vegetation at sites differing in successional age. Plant Ecology.2000(149): 43-50

[8] Huebner C D. Establishment of an invasive grass in closed-canopy deciduous forests across local and regional environmental gradients. Biological Invasions.2009(12): 2069-2080

[9] Malcolm D C, Mason W L, Clarke G C. The transformation of conifer forests in Britain-regeneration, gap size and silvicultural systems. Forest Ecology and Management.2001 (151): 7-23

[10] Jennings S B, Brown N D, Sheil D. Assessing forest canopies and understory illumination: Canopy closure, canopy cover and other measures. Forestry1999(72): 59-73.

[11] Kitajima K. Variation in crown light utilization characteristics among tropical canopy trees. Annals of Botany London.2005(95): 535-547

[12] Korhonen L, Korhonen K T, Rautiainen M. Estimation of forest canopy cover: A comparison of field measurement techniques. Silva Fennica.2006 (4) : 577-588

[13] Goodale U M et al. Disturbance and tropical pioneer species: Patterns of association across life history stages. Forest Ecology and Management.2012(277): 54-66

[14] Givnish T J. On the use of optimality arguments [G] // On the economy of plant form and function [M] .Givnish T J. Cambridge: Cambridge University Press.1986: 3-9

[15] Chazdon R L. Sun flecks and their importance to forest understory plants. Advance of Ecological Research.1988(18): 1-6

[16] Valladares F, Allen M T, Pearcy R W. Photosynthetic responses to dynamic light under field conditions in six tropical rainforest shrubs occurring along a light gradient. Oecologia.1997(111): 505-514 